\title{
Photodynamic Therapy for Circumscribed Choroidal Haemangioma in a Scottish Cohort
}

\author{
Aaron Jamison Paul Cauchi David F. Gilmour \\ Glasgow Centre for Ophthalmic Research, Tennent Institute of Ophthalmology, Gartnavel General Hospital, \\ Glasgow, UK
}

\section{Keywords}

Choroidal haemangioma - Optical coherence tomography . Photodynamic therapy - Verteporfin - Best corrected visual acuity Visual outcome

\begin{abstract}
Purpose: The aim of this study was to evaluate the safety and efficacy of photodynamic therapy (PDT) with verteporfin as a treatment for circumscribed choroidal haemangioma $(\mathrm{CCH})$. Procedures: This is a retrospective cohort study of all treatment-naïve patients undergoing PDT with verteporfin for $\mathrm{CCH}$ in a single centre between April 1, 2007, and September 30, 2016. Best corrected visual acuity (BCVA; using ETDRS letter score), optical coherence tomography (OCT) measurements and a subjective measurement of visual function were recorded before treatment, at 3-month follow-up and at each annual follow-up. Results: Seventeen Caucasian patients with $\mathrm{CCH}$ received PDT, with a re-treatment rate of $23.5 \%(n=4)$. Mean $( \pm$ SD) follow-up was $36.5( \pm 32.6)$ months (range 2-106). Mean ( \pm SD) pre-PDT BCVA was $58.5( \pm 15.5)$ letters, with a mean improvement from baseline of 8.2 letters at 3 months, of 13.8 letters at 1 year, of 21.1 letters at 2 years and of 19.5 letters at 3 years of follow-up. Subjective visual
\end{abstract}

\section{KARGER}

(c) 2018 S. Karger AG, Basel

E-Mail karger@karger.com

www.karger.com/oop improvement was noted in $67 \%$ at 3 months, in $93 \%$ at 1 year, in $86 \%$ at 2 years and in $100 \%$ at 3 years of follow-up. OCT demonstrated no intraretinal/subretinal fluid in $63 \%$ at 3 months, in $77 \%$ at 1 year, in $86 \%$ at 2 years and in $100 \%$ at 3 years of follow-up. No complications of PDT were noted during the study. Conclusions: PDT is a safe and effective treatment for $\mathrm{CCH}$ which results in both structural and functional improvements, and these findings are particularly applicable to patients of Caucasian ethnicity. OCT provides a useful and readily available option to monitor $\mathrm{CCH}$ disease activity and its response to PDT.

(c) 2018 S. Karger AG, Basel

\section{Introduction}

Choroidal haemangioma is a benign vascular tumour which presents as diffuse-type disease (typically associated with Sturge-Weber syndrome) or a circumscribed choroidal haemangioma ( $\mathrm{CCH})$. CCHs appear as an isolated orange-red rounded mass and usually arise near the posterior pole (juxtapapillary, subfoveal or parafoveal). Small asymptomatic tumours do not usually require treatment but should be monitored regularly for signs of 
Fig. 1. Retinal colour photography and OCT images of a typical example case of $\mathrm{CCH}$, with OCT images 6 weeks and 6 months after PDT showing resolution of subretinal fluid. OCT, optical coherence tomography; $\mathrm{CCH}$, circumscribed choroidal haemangioma; PDT, photodynamic therapy.
Example case

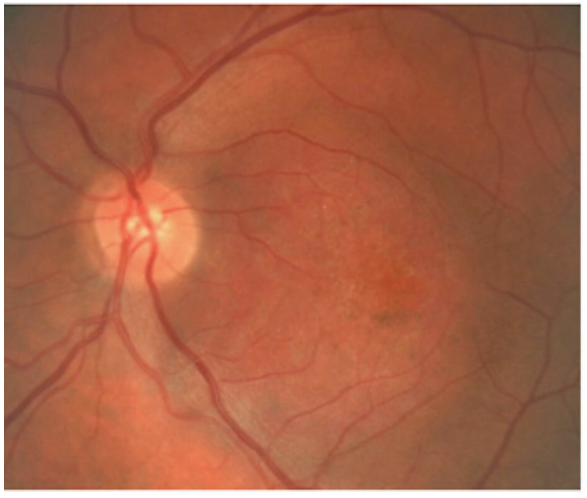

A subfoveal $\mathrm{CCH}$ prior to PDT

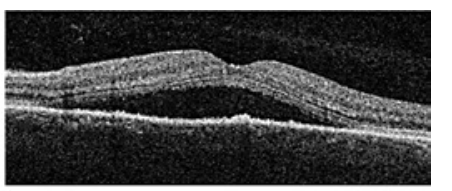

Before PDT

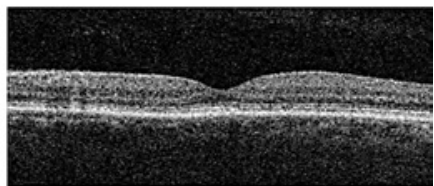

6 weeks after PDT

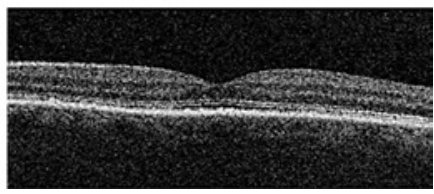

6 months after PDT progression or exudation. $\mathrm{CCH}$ can cause significant visual impairment when exudative activity leads to the development of macular oedema and/or serous retinal detachment and, eventually, photoreceptor loss. Treatment of symptomatic or exudative $\mathrm{CCH}$ should be considered in order to protect vision.

Many treatment modalities have been utilised in the management of choroidal haemangioma, including laser photocoagulation, cryotherapy, external beam radiotherapy, proton beam radiotherapy, plaque brachytherapy and transpupillary thermotherapy (TTT) [1]. Although many of these have proven effective at stabilising or improving exudative activity, the stabilisation and restoration of visual function has been less convincing, due to the inability of such treatments to avoid injury to adjacent tissues, such as Bruch's membrane and the neurosensory retina.

Verteporfin (Visudyne, Novartis) is a benzoporphyrin-derivative photosensitiser. When stimulated by light with $690 \mathrm{~nm}$ wavelength, it undergoes a photochemical reaction producing highly reactive short-lived singlet oxygen and other reactive oxygen radicals. Photodynamic therapy (PDT) with verteporfin offers selective laser stimulation of choroidal vascularised structures, as has been seen previously in the treatment of choroidal neovascularisation (CNV) [2]. This selective targeting of abnormal vascularised tissue within the choroid has made PDT a logical option in the management of $\mathrm{CCH}$, and several case series have demonstrated its safety and efficacy [312].

The authors report the safety and efficacy of PDT in 17 patients with CCH treated between April 1, 2007, and September 30,2016, using optical coherence tomography (OCT) to monitor disease activity and response to treatment.

\section{Methods}

All patients were referred to Gartnavel General Hospital, a tertiary referral centre, and confirmed to have a $\mathrm{CCH}$ by a combination of fundoscopy, retinal colour photography, fundus fluorescein angiography and ocular ultrasound. All treatment-naïve patients receiving $\mathrm{PDT}$ for $\mathrm{CCH}$ in this single centre between January 2007 and September 2016 were included in this retrospective review.

Patients received intravenous infusion of verteporfin $(6 \mathrm{mg} /$ $\mathrm{m}^{2}$ ) followed, $15 \mathrm{~min}$ later, by administration of diode laser $(690$ $\mathrm{nm})$ with $600 \mathrm{~mW} / \mathrm{cm}^{2}$ irradiance and a duration of $83 \mathrm{~s}(50 \mathrm{~mJ} /$ $\mathrm{cm}^{2}$ fluence) over the entire tumour surface. The diameter of the treatment zone was based on the maximum diameter of the choroidal haemangioma itself, and in cases where the tumour was larger than the maximum spot size, 2 or more applications were applied, taking care to minimise the overlap of applications while ensuring treatment of the entire surface area. Application over the optic nerve was avoided. Figure 1 shows the response of a typical $\mathrm{CCH}$ to PDT.

Best corrected visual acuity (BCVA), using ETDRS letter score, and OCT measurements were recorded prior to treatment and as close as possible to 3-month follow-up and each subsequent annual 
Table 1. Baseline clinical features

\begin{tabular}{rllllll}
\hline Case & $\begin{array}{l}\text { Age, } \\
\text { years }\end{array}$ & Sex & Laterality & $\begin{array}{l}\text { Lesion } \\
\text { location }\end{array}$ & $\begin{array}{l}\text { Symptom duration at } \\
\text { time of PDT, months }\end{array}$ & $\begin{array}{l}\text { Pre-PDT BCVA, ETDRS } \\
\text { [Snellen equivalent] }\end{array}$ \\
\hline 1 & 54 & $\mathrm{~m}$ & $\mathrm{r}$ & subfoveal & 1 & $75[6 / 9.5]$ \\
2 & 49 & $\mathrm{~m}$ & $\mathrm{l}$ & parafoveal & 108 & $55[6 / 24]$ \\
3 & 42 & $\mathrm{~m}$ & $\mathrm{r}$ & subfoveal & 21 & $55[6 / 24]$ \\
$4^{\mathrm{a}}$ & 70 & $\mathrm{~m}$ & $\mathrm{r}$ & subfoveal & 8 & $55[6 / 24]$ \\
5 & 32 & $\mathrm{~m}$ & $\mathrm{l}$ & subfoveal & not known & $60[6 / 18]$ \\
6 & 51 & $\mathrm{f}$ & $\mathrm{r}$ & subfoveal & 5.5 & $70[6 / 12]$ \\
7 & 52 & $\mathrm{~m}$ & $\mathrm{l}$ & subfoveal & not known & $78[\sim 6 / 7.5]$ \\
8 & 51 & $\mathrm{f}$ & $\mathrm{l}$ & subfoveal & 23 & $71[\sim 6 / 12]$ \\
9 & 83 & $\mathrm{f}$ & $\mathrm{l}$ & subfoveal & 29 & $60[6 / 18]$ \\
10 & 56 & $\mathrm{~m}$ & $\mathrm{r}$ & parafoveal & 5.5 & $67[\sim 6 / 15]$ \\
11 & 73 & $\mathrm{f}$ & $\mathrm{r}$ & parafoveal & 5 & $55[6 / 24]$ \\
12 & 60 & $\mathrm{~m}$ & $\mathrm{r}$ & subfoveal & 18 & $76[6 / 24]$ \\
13 & 74 & $\mathrm{~m}$ & $\mathrm{r}$ & juxtapapillary & 50 & $67[\sim 6 / 15]$ \\
14 & 58 & $\mathrm{~m}$ & 1 & subfoveal & 15 & $35[6 / 60]$ \\
15 & 48 & $\mathrm{f}$ & $\mathrm{l}$ & subfoveal & 25 & $40[6 / 48]$ \\
16 & 45 & $\mathrm{f}$ & $\mathrm{l}$ & subfoveal & 14 & $20[3 / 60]$ \\
17 & 56 & $\mathrm{~m}$ & $\mathrm{r}$ & parafoveal & 38 & \\
\hline
\end{tabular}

BCVA, best corrected visual acuity; PDT, photodynamic therapy. ${ }^{\text {a }}$ Initially diagnosed and managed as $\mathrm{CCH}$ but later believed to be a choroidal neovascularisation; see section Adverse Events.

follow-up. OCT measurements were recorded with the aim to evaluate secondary morphological changes of the retina and included central retinal thickness, retinal thickness overlying the $\mathrm{CCH}$ and the presence of subretinal or intraretinal fluid. In addition, subjective measurement of visual function (obtained by asking patients whether their vision had changed since treatment with PDT), complications and any required re-treatments were recorded.

Linear regression analysis was performed to identify any relationship between the change in ETDRS letter score, from prior to treatment to each follow-up time point, and 1 of 2 variables: (1) duration of symptoms at the time of first PDT treatment; (2) the "delay" to treatment (the time from first presentation to the service to first PDT application). Standard weighted one-way analysis of variances (ANOVA) was performed to identify any effect of tumour location (subfoveal, parafoveal or juxtapapillary) on the change in ETDRS letter score at each follow-up time point. F statistics are presented in standardised format as suggested by the American Psychological Association ("APA style"). Statistical analysis was performed using Analysis ToolPak.

Prior to the study being performed, the institutional review board/ethics committee ruled that approval was not required. The study adhered to the tenets of the Declaration of Helsinki.

\section{Results}

Seventeen treatment-naïve patients with $\mathrm{CCH}$ were treated with PDT between April 1, 2007, and September 30,2016 . Two further patients were excluded from the study as they had received prior treatment for $\mathrm{CCH}$. All of the patients were British and of Caucasian ethnicity. The mean age was 56 years (range $32-83$ ) with a male preponderance $(n=11)$. A mean follow-up of 36.5 months was achieved (median 19.0 months, range 2-106). Baseline clinical features are detailed in Table 1.

\section{Visual Acuity}

Mean $( \pm$ SD) BCVA was $58.5( \pm 15.5)$ letters prior to treatment, and there was a mean improvement from baseline of 8.2 letters at 3 months, of 13.8 letters at 1 year, of 21.1 letters at 2 years and of 19.5 letters at 3 years of follow-up (Fig. 2). A subjective improvement in vision was reported by $67 \%(n=10 / 15)$ of patients at 3 months, by $93 \%(n=13 / 14)$ at 1 year, by $86 \%(n=6 / 7)$ at 2 years and by $100 \%(n=6 / 6)$ at 3 years of follow-up. Of the 15 patients with visual acuity data at the first follow-up after PDT, 10 showed some improvement in visual acuity. Two patients showed no change in visual acuity: 1 was noted to have macular retinal pigment epithelium changes associated with their $\mathrm{CCH}$ (case 11), and the other had reported the onset of visual symptoms 3 years prior to presentation (case 17). Three patients had reduced visual acuity at their first follow-up visit. Two of these cases showed improvement at subsequent followup visits: 1 returned almost back to their baseline BCVA 
BCVA measurements (ETDRS letter scores)

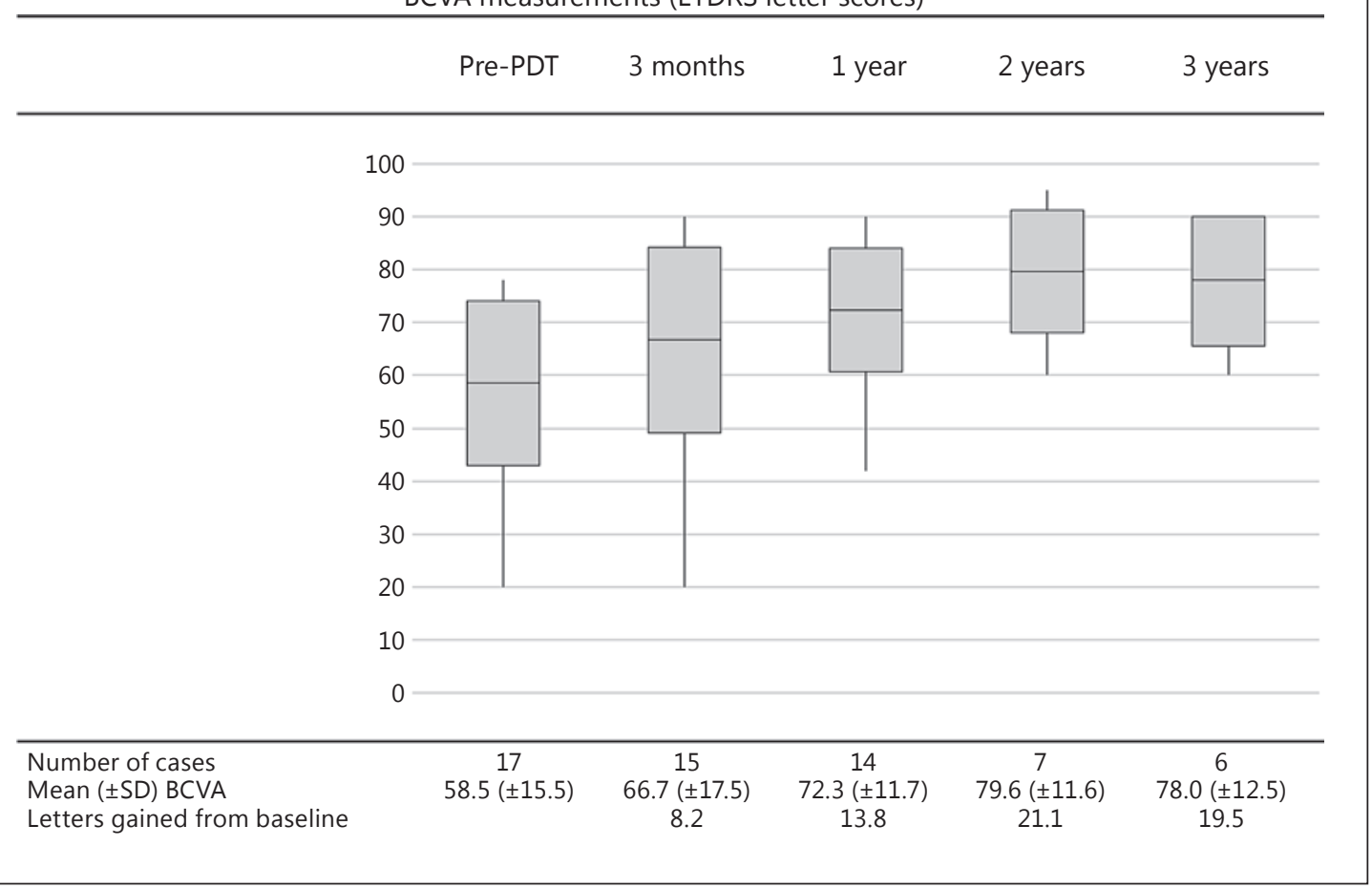

Fig. 2. BCVA measurements (using ETDRS letter scores) prior to PDT and at each post-procedure follow-up time point. Box midline indicates mean BCVA (ETDRS). Upper and lower boxplot limits indicate 1 SD from the mean. Upper and lower whisker limits indicate maximum and minimum BCVA values. BCVA, best corrected visual acuity; PDT, photodynamic therapy; SD, standard deviation.

(case 7), and 1 exceeded their baseline BCVA (case 9). The third of these patients (case 12) was amblyopic in the treated eye and did not notice the mild reduction in visual acuity.

Only 1 patient not mentioned above (case 4) went on to lose vision after their first follow-up. This reduction in visual acuity occurred around 60 months after PDT treatment and was felt to be secondary to CNV. This case is discussed in further detail in the Adverse Events section.

Figure 3 charts the duration of symptoms at the time of the first PDT treatment with the change in ETDRS letter score from prior to treatment to each follow-up time point. For the purposes of this specific analysis, 1 patient with symptoms that preceded their PDT treatment by 9 years was excluded. Linear regression analysis revealed $R^{2}$ values of $0.0045(p=0.83)$ at 3 -month follow-up, 0.0023 $(p=0.89)$ at 1 -year follow-up and $0.00004(p=0.99)$ at 2 -year follow-up, indicating that "duration of symptoms prior to treatment" is not a predictor of visual outcome at 3-month, 1-year or 2-year follow-up. The same analysis showed a greater correlation at 3-year follow-up $\left(R^{2}=\right.$ $0.7239, p=0.14)$. However, the significance of all of these results, as demonstrated by the reported 2-tailed $p$ values, is limited by the low numbers of cases included in the analysis.

A similar analysis was also performed to identify any relationship between "delay" to treatment (the time from first presentation to the service to first PDT application) and change in ETDRS letter score after treatment, and this showed no relationship at any post-treatment time point.

Our cases were further subdivided to show the effect of tumour location (subfoveal, parafoveal or juxtapapillary) on the change in ETDRS letter score at each followup time point (Table 2). Patients with subfoveal choroidal haemangiomas experienced the greatest mean improvement in ETDRS letter score at 3-month and 1-year follow-up, although a standard weighted one-way analysis of variances (ANOVA) showed there to be no statisti- 


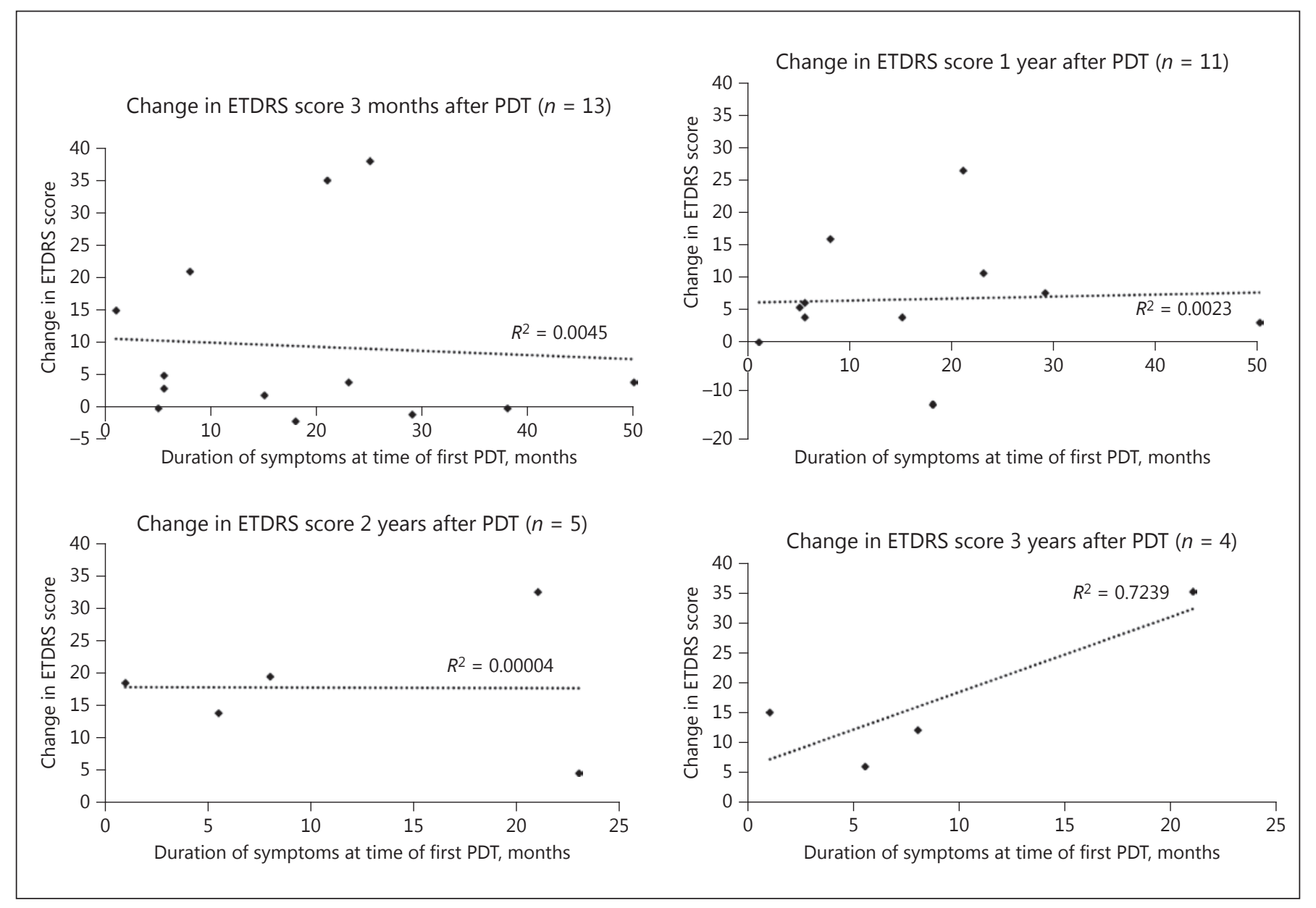

Fig. 3. Simple linear regression of "duration of symptoms at time of first PDT" with "change in ETDRS score" at 3 months, 1 year, 2 years and 3 years of follow-up. One patient with symptoms that preceded their PDT treatment by 9 years was excluded from this analysis. PDT, photodynamic therapy.

cally significant difference at either time point: $F(2,12)=$ $0.33, p=0.73$, at 3 months and $F(2,11)=0.10, p=0.90$, at 1 year. Statistical comparison at 2- and 3-year followup was not possible as only 1 group (subfoveal lesions) had data for more than 1 case.

\section{OCT Measurements}

Mean $( \pm$ SD) central retinal thickness was $316( \pm 74)$ $\mu \mathrm{m}$ prior to treatment, $235( \pm 49) \mu \mathrm{m}$ at 3 -month followup, $243( \pm 81) \mu \mathrm{m}$ at 1 year, $266( \pm 35) \mu \mathrm{m}$ at 2 years and $303( \pm 54) \mu \mathrm{m}$ at 3 years. Mean $( \pm S D)$ central retinal lesion thickness (i.e., the greatest thickness of the retina overlying the $\mathrm{CCH})$ was $440( \pm 154) \mu \mathrm{m}$ prior to treatment and was also reduced at all follow-up time points: 3 months, $280( \pm 54) \mu \mathrm{m} ; 1$ year, $282( \pm 145) \mu \mathrm{m} ; 2$ years, $350( \pm 73)$ $\mu \mathrm{m}$; 3 years, $365( \pm 30) \mu \mathrm{m}$.
All patients had subretinal fluid noted on OCT imaging prior to PDT treatment. No subretinal or intraretinal fluid was seen in $63 \%$ of the patients $(n=10 / 16)$ at 3 months, in $77 \%(n=10 / 13)$ at 1 year, in $86 \%(n=6 / 7)$ at 2 years and in $100 \%(n=6 / 6)$ of those achieving 3 -year follow-up.

\section{Follow-Up}

A mean $( \pm$ SD) follow-up of $36.5( \pm 32.6)$ months was achieved (median 19.0 months, range 2-106). During this period, 4 patients required re-treatment with PDT, resulting in a re-treatment rate (calculated based on the number of patients requiring at least 1 further treatment) of $23.5 \%$ (Table 3). Two patients received a single re-treatment with PDT: case 1, at 17 months after initial PDT; case 4, at 60 months. One patient required 2 further re-treatments 
Table 2. Change in ETDRS letter score by tumour location

\begin{tabular}{lllll}
\hline Follow-up duration & Subfoveal & Parafoveal & Juxtapapillary & One-way ANOVA $^{\mathrm{a}}$ \\
\hline 3 months & $9.4 \pm 18.3(n=10)$ & $2.0 \pm 2.4(n=4)$ & $4.0(n=1)$ & $F(2,12)=0.33, p=0.725^{\mathrm{b}}$ \\
1 year & $8.9 \pm 13.4(n=10)$ & $6.7 \pm 1.5(n=3)$ & $4.0(n=1)$ & $F(2,11)=0.10, p=0.906^{\mathrm{c}}$ \\
2 years & $15.5 \pm 13.3(n=6)$ & $5.0(n=1)$ & not available $(n=0)$ & $\begin{array}{l}\text { not available } \\
\text { not available }\end{array}$ \\
3 years & $18.6 \pm 11.5(n=5)$ & $5.0(n=1)$ & not available $(n=0)$ & \\
\hline
\end{tabular}

Values are means \pm standard deviation. ${ }^{a}$ One-way analysis of variance. ${ }^{b}$ No statistically significant difference. ${ }^{c}$ No statistically significant difference.

Table 3. Post-procedure details

\begin{tabular}{rrll}
\hline Case & $\begin{array}{l}\text { Length of follow-up, } \\
\text { months }\end{array}$ & Re-treatments & Complications \\
\hline 1 & 78.1 & $1 \times$ PDT $(17$ months after initial PDT $)$ & none \\
2 & 106.2 & nopDT $(26$ and 55 months after initial PDT $)$ & none \\
3 & 79.3 & none & none (see section Adverse Events $)$ \\
4 & 71.5 & $1 \times$ PDT $(60$ months after initial PDT $)$ & none \\
5 & 67.0 & 1× PDT $(50$ months after initial PDT $)$ & none \\
& & none & none \\
6 & 49.7 & none & none \\
7 & 41.9 & none & none \\
8 & 28.0 & none & none \\
9 & 19.0 & none & none \\
10 & 15.0 & none & none \\
11 & 14.2 & none & none \\
12 & 14.0 & none & none \\
13 & 13.7 & none & none \\
14 & 10.7 & none & none \\
15 & 6.4 & none & none \\
16 & 2.3 & none & \\
17 & 2.8 & &
\end{tabular}

PDT, photodynamic therapy; TTT, transpupillary thermotherapy.

with PDT: case 2, at 26 and 55 months. One further case required a single re-treatment with $\mathrm{PDT}$ and a TTT application: case 5, TTT at 47 months, PDT at 50 months.

In the management of case 5, initial PDT was felt to have been unsuccessful due to the re-accumulation of intraretinal fluid, and TTT was applied at the discretion of the clinician. Following non-response to this TTT, the patient then continued on to re-treatment with PDT 3 months later, which resulted in complete resolution of the intraretinal fluid associated with an improvement in visual acuity.

Re-treatment was required due to increasing subretinal and intraretinal fluid (cases 1, 2, 4 and 5), associated with reduced visual acuity in cases 4 and 5. These 4 patients had differing durations of symptoms prior to treat- ment, tumour locations and pre-operative visual acuity. Multivariate regression analysis was performed, confirming that 1 or more of these 3 factors could not be used to predict the requirement of future re-treatment.

\section{Adverse Events}

One patient (case 4), receiving a second PDT 60 months after their original treatment, was noted to have developed an area of advanced CNV 3 months after their procedure (Fig. 4). An area of new intraretinal fluid had been identified prior to the second PDT which was thought to be secondary to reactivation of the $\mathrm{CCH}$. However, after reviewing the OCT images, it was felt that $\mathrm{CNV}$ was also present at this stage. $\mathrm{CNV}$ is a rare but recognised complication of $\mathrm{CCH}[13,14]$. Although it is pos- 


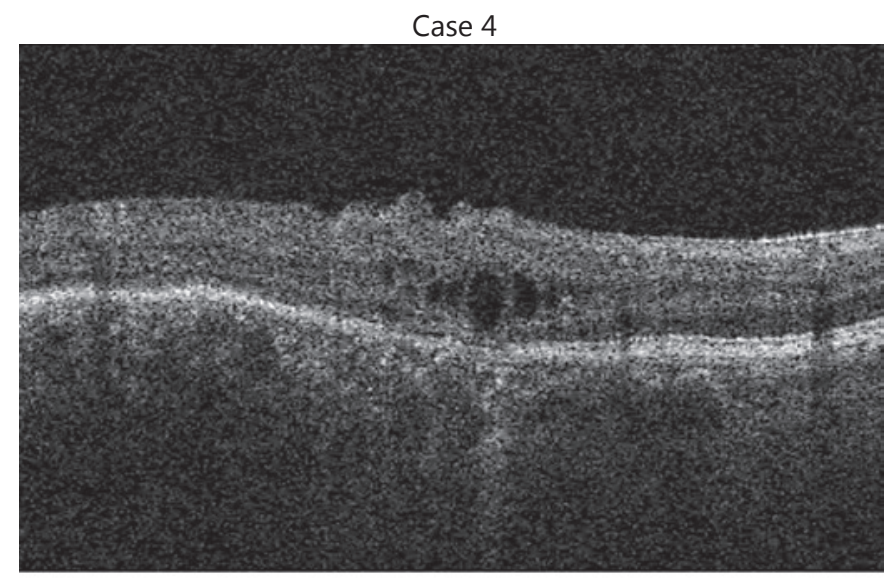

Pre-PDT macular OCT

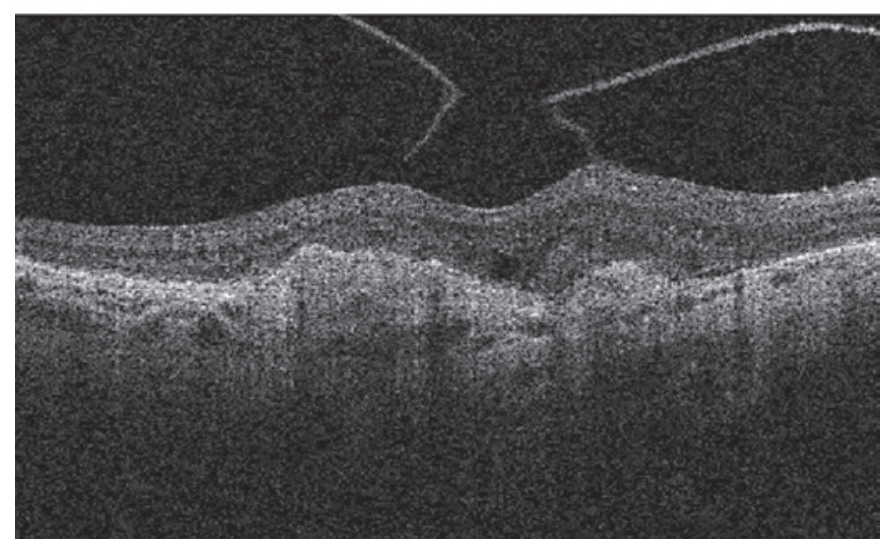

Post-PDT macular OCT

Fig. 4. Macular OCT images before and after a second application of PDT suggest the presence of an advanced choroidal neovascularisation, associated with atrophy and scarring at the fovea. OCT, optical coherence tomography; PDT, photodynamic therapy.

sible that the $\mathrm{CNV}$ is secondary to the first PDT treatment, it is more likely that it occurred spontaneously as part of the natural history of the $\mathrm{CCH}$ disease. Clinicians should look carefully for signs of CNV during the followup of $\mathrm{CCH}$ patients following PDT as CNV activity may be mistaken for $\mathrm{CCH}$ activity, and intravitreal anti-VEGF therapy is the preferred treatment in these cases.

\section{Discussion}

Blasi et al. [3] have published a case series of PDT in 25 treatment-naïve patients with $\mathrm{CCH}$, with 5-year follow-up. This was the first publication to measure and monitor secondary retinal changes before and after treat- ment with PDT. Twelve percent of the patients required re-treatment with PDT. All patients showed a persistent reduction in OCT macular thickness measurements at 5 -year follow-up, although no data were provided between 12 and 60 months.

Several other case series and case reports demonstrate that PDT is a safe and effective treatment for $\mathrm{CCH}$, without OCT measurements, and with limited followup [4-12]. Jurklies et al. [4] present 19 patients with $\mathrm{CCH}$ treated with PDT with a mean follow-up of 10.6 months. Four of these patients had received previous treatments for $\mathrm{CCH}$. They noted improvement of visual acuity in $73.3 \%$ and regression of tumour height (measured by ophthalmic ultrasound) in all patients. They were also able to demonstrate that patients who had received previous PDT treatments, with a baseline visual acuity of $0.1 \log$ MAR or less, a history of more than 30 months, or no significant response after the first PDT session, did not show a significant improvement of visual acuity of at least 2 lines. Schmidt-Erfurth et al. [5] demonstrated complete tumour regression in all of their patients after $\operatorname{PDT}(n=15)$ and visual improvement in 13 cases, with a mean follow-up of 19 months. Verbraak et al. [6] reported improved visual acuity in 11 treatment-naïve patients and tumour height regression in all patients, with a median follow-up of 12 months. Among the reports of PDT in the treatment of $\mathrm{CCH}$, re-treatment rates varied from $0 \%(n=3)$ to $90 \%(n=10)$, although these rates will be affected by the treatment protocols adopted in each specific unit. All of the identified papers that describe treatment of $\mathrm{CCH}$ with PDT report positive results.

In this study, the safety and efficacy of PDT in 17 treatment-naïve $\mathrm{CCH}$ patients is presented with a mean follow-up of 36.5 months. Following PDT, the patients achieved excellent structural and functional results, with a re-treatment rate of $23.5 \%$.

Most patients reported an improvement in their vision, with a mean improvement of ETDRS letter score from baseline of 8.2 letters at 3 months, of 13.8 letters at 1 year, of 21.1 letters at 2 years, and of 19.5 letters at 3 years of follow-up.

Scotland has a relatively stable population with low migration rates: Scotland's Census 2011 reported a 4\% representation of minority ethnic groups. That all of the studied patients were of Caucasian ethnicity is, therefore, broadly representative of the Scottish population. The descriptions of the response of $\mathrm{CCH}$ to PDT found in this paper will be particularly applicable to patients of Caucasian ethnicity. 
This study is among the first to measure and monitor the degree of retinal morphological change secondary to $\mathrm{CCH}$, before and after treatment with PDT using OCT. The authors believe that, in the context of $\mathrm{CCH}$, OCT provides a useful and readily available option to monitor disease activity and response to treatment with PDT.

Mean OCT measurements demonstrated decreasing retinal thickness, with effect greatest at 3 months. This was followed by a second phase in which mean retinal thickness gradually increased, almost to pre-PDT measurements, over the remaining follow-up period. Although reflected in the mean OCT measurements, this effect was restricted to 5 specific patients. These cases were notable for having received at least 2 years of follow-up, although no pattern of their baseline characteristics (i.e., age, gender, pre-treatment visual acuity and OCT measurements, tumour location and duration of symptoms at time of first treatment) was evident. Only 1 patient (case 2) actually returned to, and exceeded, pre-PDT measurements, and they received 2 further re-treatments with PDT (at 26 and 55 months after the initial PDT) due to visual deterioration and evidence of $\mathrm{CCH}$ activity, as indicated by the presence of subretinal fluid. The remaining cases that showed some increase in retinal thickness over the followup period did not reach pre-PDT measurements and were re-treated based on the presence of subretinal/intraretinal fluid with reduced visual acuity and/or the subjective impression of visual deterioration (Table 3 ).

Our study considered whether visual outcomes may be influenced by the duration of symptoms prior to treatment or the tumour location (subfoveal, parafoveal or juxtapapillary), but no statistically significant associations were identified for either. This contrasts with the findings of Jurklies et al. [4] who found that final visual outcome depends on the duration of symptoms before the first PDT treatment - although this finding was not reproducible in a Cox regression analysis. Study of a larger cohort is likely to help clarify whether this relationship exists.

No complications were noted during the study period. During follow-up, 1 patient was noted to have developed advanced CNV which was initially misdiagnosed as recurrence of choroidal haemangioma activity.

Limitations of this study include a small number of patients, although comparable in size to the largest existing papers that consider PDT in the treatment of choroidal haemangioma. Low case numbers combined with uneven distribution of cases among the 3 tumour location groups made statistical analysis for significant differences difficult.

PDT for Circumscribed Choroidal Haemangioma

Although no statistically significant differences were noted between the 3 tumour location groups reported, the mean improvement in ETDRS letter score was greatest in those with subfoveal choroidal haemangioma. These data support the argument that PDT is suitable for use with subfoveal choroidal haemangiomas as it is able to preserve foveal function where previously popular treatments, such as laser photocoagulation and TTT, cannot. When combined with the relative ease of treatment administration and the availability of PDT in most oncology treatment centres, PDT is the safest and most effective treatment modality in the management of $\mathrm{CCHs}$ and, in particular, in those affecting the posterior pole.

PDT with verteporfin is a safe and effective treatment for $\mathrm{CCH}$. Four patients required re-treatment with PDT (re-treatment rate 23.5\%) due to re-accumulation of subretinal/intraretinal fluid and/or reduced visual acuity. Our results demonstrate that treatment with PDT results in both structural and functional improvements, and these findings are particularly applicable to patients of Caucasian ethnicity. OCT provides a useful and readily available option to monitor $\mathrm{CCH}$ disease activity and its response to PDT.

\section{Statement of Ethics}

This study did not require approval by an ethics committee but adheres to the principles of the Declaration of Helsinki.

\section{Disclosure Statement}

The authors have no financial disclosures or sources of funding to report.

References

Ocul Oncol Pathol 2018;4:322-330 DOI: $10.1159 / 000486340$
1 Anand A, Augsburger JJ, Shields JA: Circumscribed choroidal haemangiomas. Arch Ophthalmol 1989;107:1338-1342.

2 Schmidt-Erfurth U, Hasan T: Mechanisms of action of photodynamic therapy with verteporfin for the treatment of age-related macular degeneration. Surv Ophthalmol 2000;45: 195-214.

3 Blasi MA, Tiberti AC, Scupola A, Balestrazzi A, Colangelo E, Valente P, Balestrazzi E: Photodynamic therapy with verteporfin for symptomatic circumscribed choroidal haemangioma: five-year outcomes. Ophthalmology 2010;117:1630-1637. 
4 Jurklies B, Anastassiou G, Ortmans S, Schüler A, Schilling H, Schmidt-Erfurth U, Bornfeld $\mathrm{N}$ : Photodynamic therapy using verteporfin in circumscribed choroidal haemangioma. $\mathrm{Br}$ J Ophthalmol 2003;87:84-89.

5 Schmidt-Erfurth UM, Michels S, Kusserow C, Jurklies B, Augustin AJ: Photodynamic therapy for symptomatic choroidal hemangioma: visual and anatomic results. Ophthalmology 2002;109:2284-2294.

6 Verbraak FD, Schlingemann RO, Keunen JE, de Smet MD: Longstanding symptomatic choroidal hemangioma managed with limited PDT as initial or salvage therapy. Graefes Arch Clin Exp Ophthalmol 2003;241:891898.
7 Barbazetto I, Schmidt-Erfurth U: Photodynamic therapy of choroidal haemangioma: two case reports. Graefes Arch Clin Exp Ophthalmol 2000;238:214-221.

8 Gupta M, Singh AD, Rundle PA, Rennie IG: Efficacy of photodynamic therapy in circumscribed choroidal haemangioma. Eye 2004; 18:139-142.

9 Madreperla SA: Choroidal haemangioma treated with photodynamic therapy using verteporfin. Arch Ophthalmol 2001;119: $1606-1610$

10 Landau IME, Steen B, Seregard S: Photodynamic therapy for circumscribed choroidal haemangioma. Acta Ophthalmol Scand 2002; 80:531-536.
11 Singh AD, Kaiser PK, Sears JE, Gupta M, Rundle PA, Rennie IG: Photodynamic therapy of circumscribed choroidal haemangioma. Br J Ophthalmol 2004;88:1414-1418.

12 Porrini G, Giovannini A, Amato G, Ioni A, Pantanetti M: Photodynamic therapy of circumscribed choroidal haemangioma. Ophthalmology 2003;110:674-680.

13 Shields Cl, Honavar SG, Shields JA, Cater J, Demirci H: Circumscribed choroidal hemangioma: clinical manifestations and factors predictive of visual outcome in 200 consecutive cases. Ophthalmology 2001;108:22372248.

14 Querques G, Forte R, Querques L, Souied EH: Intravitreal ranibizumab for choroidal neovascularisation associated with circumscribed choroidal haemangioma. Clin Exp Ophthalmol 2011;39:916-918. 